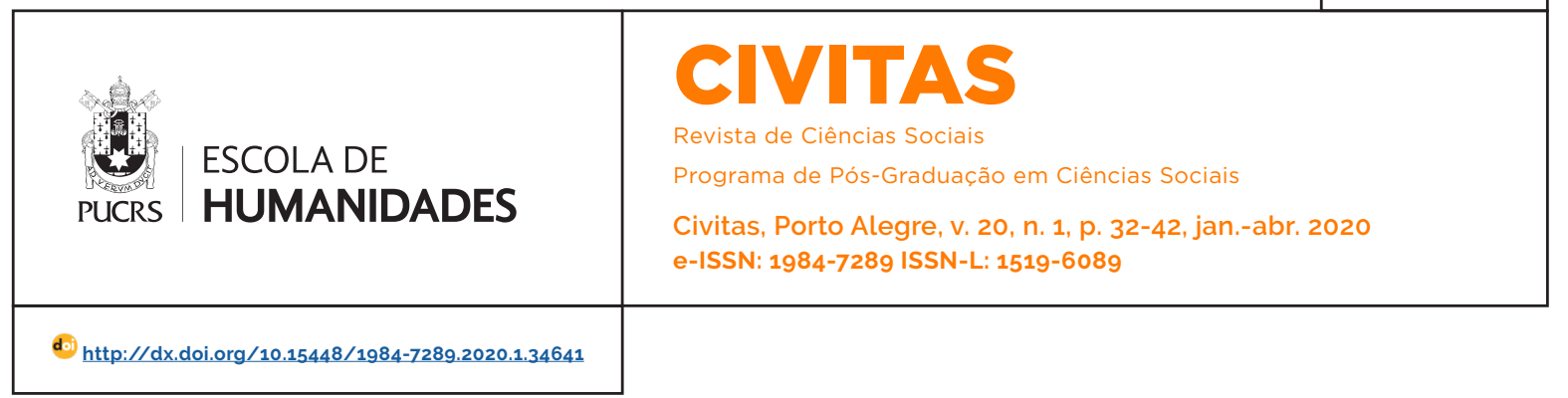

DOSSIÊ: OS NOVOS DESAFIOS DO DESENVOLVIMENTO NA REGIÃO AMAZÔNICA

\title{
Desenvolvimento regional e aceitabilidade social de grandes projetos de infraestrutura: o caso da Câmara Técnica de saúde do PDRS do Xingu
}

\author{
Regional development and social acceptability of large infrastructure projects: the case \\ of the PDRS Xingu Health Technical Chamber \\ Desarrollo regional y aceptabilidad social de grandes proyectos de infraestructura: el \\ caso de la Cámara Técnica de Salud del PDRS Xingu
}

\author{
Márcia Grisotti ${ }^{1}$ \\ orcid.org/0000-0003-0389-7100 \\ grisotti@fastlane.com.br
}

\section{Marina Reche Felipe ${ }^{1}$}

orcid.org/0000-0003-4931-8522

marinareche@hotmail.com

André Marconato Ramos ${ }^{2}$

orcid.org/0000-0001-9993-7853

andreramos20@gmail.com

Recebido em: 12 set. 2019

Aprovado em: 4 nov. 2019

Publicado em: 25 mai. 2020
Resumo: O artigo analisa o processo de aceitabilidade social da Usina Hidrelétrica de Belo Monte e as disputas em torno da responsabilização pelos impactos à saúde através da análise da Câmara Técnica de Saúde do Plano de Desenvolvimento Regional Sustentável do Xingu. A análise sobre a gestão desse Plano evidenciou como as relações imprecisas e conflituosas entre os setores públicos e privados afetaram as atribuições de responsabilidades em relação aos impactos socioambientais. Constatamos que as assimetrias de poder entre os grupos sociais e entre as agências de governo, as relações público-privadas, as fragilidades do pacto federativo brasileiro e a tendência para a sobreposição de esforços em participação social, sem articulação com os mecanismos de participação e controle sociais já existentes, tendem a elucidar os motivos da baixa eficácia do Plano para garantir a sustentabilidade regional do território impactado por Belo Monte. Palavras-chave: Aceitabilidade social. Participação social. Hidrelétricas. Belo Monte.

Abstract: The article analyzes the process of social acceptability of the Belo Monte hydroelectric power plant and the disputes about the responsibility for health impacts through the analysis of the technical health chamber of the Sustainable Regional Development Plan of the Xingu. The analysis of the management process of this Plan evidenced how the inaccurate and conflicting relations between the public and private sectors affected attributions of responsibilities in mitigating social and environmental impacts. We find that the asymmetries of power between social groups and government agencies, the public-private relations, the weaknesses of the Brazilian federal pact and the tendency to overlap efforts in social participation, without articulation with existing mechanisms of participation and social control, tend to explain the reasons for the low effectiveness of the Plan to guarantee the regional sustainability of the territory impacted by Belo Monte. Keywords: Social acceptability. Social participation. Hydroelectric. Belo Monte.

Resumen: El artículo analiza el proceso de aceptabilidad social de la usina hidroeléctrica de Belo Monte y las disputas en torno a la responsabilización por los impactos a la salud a través del análisis de la cámara técnica de salud del Plan de Desarrollo Regional Sostenible del Xingu. El análisis del processo de géstion de este Plan evidenció como las imprecisas y conflictivas relaciones entre los sectores públicos y privados afectaron atribuciones de responsabilidades en relación a los impactos socioambientales. Constatamos que las asimetrias de poder entre los grupos sociales y entre las agencias de gobierno, las relaciones público-privadas, las fragilidades del pacto federativo brasileño y la tendencia a la superposición de esfuerzos en participación social, sin articulación con los mecanismos de participación y control social ya existentes, tienden a elucidar los motivos de la baja eficacia del Plan para garantizar la sostenibilidad regional del territorio impactado por Belo Monte. Palabras clave: Aceptabilidad social. Participación social. Hidroeléctrica. Belo Monte.
Artigo está licenciado sob forma de uma licença Creative Commons Atribuição 4.0 Internacional. 


\section{Introdução}

A região amazônica possui uma importância fundamental nas diretrizes geopolíticas e econômicas do País e, durante várias décadas, partes de seu território foram escolhidos para fomentar diferentes ciclos econômicos. As ondas de ocupação e exploração territorial, portanto, não são necessariamente novas. A novidade é que as intervenções nessa região atualmente são influenciadas por uma convergência neodesenvolvimentista, marcada por um aumento do número de projetos construídos simultaneamente com grande aporte financeiro estatal, por uma nova coordenação panamazônica e por uma relação nebulosa entre estado e empresas parceiras privadas (Castro 2012; Fuchs, Leturcq e Grisotti 2006). Nesse contexto, o estado brasileiro retomou mais fortemente o seu papel de empreendedor reacendendo o debate sobre o modelo de "capitalismo politicamente orientado", criticado há décadas por Faoro (2000) ou "capitalismo de estado", desenvolvido na literatura contemporânea (Musacchio e Lazzarini 2015).

A geração de energia é considerada como fundamental para o crescimento econômico de um pais. Por essa razão, o Governo Federal por meio do Plano de Aceleração do Crescimento (PAC), criado durante o segundo mandato do Presidente Lula (2007-2010), reativou a execução de grandes projetos de infraestrutura. Dentre os projetos do PAC constava a implantação de uma série de usinas hidrelétricas nos rios amazônicos. Contudo, apesar da justificável necessidade de produção de energia, a configuração do PAC e o processo de implementação de suas obras não está isento de controvérsias e problemas. Castro (2012) destaca que o PAC foi uma reformulação do modelo de desenvolvimento da fronteira amazônica, implementado a partir da década de 1970, o qual ocasionou a deflagração de diversos conflitos socioambientais, bem como, a intensificação do desmatamento e da exploração de recursos naturais da região. Moran (2016) compara dois grandes ciclos de crescimento populacional da cidade de Altamira, Pará, ao demonstrar a semelhança entre os impactos provocados no início da década de 1970, quando a cidade foi transformada pela chegada de construtores da estrada Transamazônica e de colonos que passaram a habitar na região (no âmbito do Programa de Integração Geopolítica da Região Amazônica dentro das metas de desenvolvimento nacional), com o ano de 2010, quando o Governo Federal, através do PAC, investiu massivamente na construção da hidrelétrica de Belo Monte, no Rio Xingu, tendo a cidade de Altamira que arcar com a maior parte dos impactos sociais negativos oriundos dessa tomada de decisão.

Entre as décadas de 1970 e 2010, estudos sobre os impactos das usinas hidrelétricas foram publicados por especialistas e organismos internacionais, desde aqueles que apontavam os altos custos sociais e ambientais decorrentes da implantação das usinas (Cernea 1999; Scudder 1997: Fearnside 2001; Vainer 2007; Berman 2012), os quais os organismos internacionais de financiamento passaram a condicionar aportes financeiros dos projetos à aplicação efetiva dos instrumentos de política ambiental, até aqueles que criticavam o mito das hidrelétricas como energia limpa, citando Belo Monte como fonte de emissão de gases de efeito estufa (Fearnside 2017).

Apesar das críticas ao Estudo de Impacto Ambiental e Relatório de Impacto Ambiental (EIARima), das falhas do processo de licenciamento (que chancelaram as licenças de instalação e operação), da falta de uma intensa consulta pública prévia e informada (como demandado pela Convenção 169 da Organização Internacional do Trabalho, no caso dos povos indígenas, e pela Constituição de 1988 e pelas recomendações da Comissão Mundial de Barragens, para toda a população brasileira) e das amplas manifestações sociais contrárias à obra, a Usina Hidrelétrica de Belo Monte, no entanto, foi construida na Bacia do Rio Xingu, no estado brasileiro do Pará; sendo considerada a terceira maior hidrelétrica do mundo, e uma das obras prioritárias do PAC.

Uma análise sobre as condições que efetivamente tornaram possivel essa tomada de decisão e o estudo das lacunas do processo de governança de grandes 
projetos de desenvolvimento no Brasil precisam ser aprofundadas. A maior parte dos estudos foca nos processos de licenciamento ilustrando o confronto de diferentes concepções acerca do que caracteriza determinado território ou recurso natural de uso comum e suas diferentes formas de uso e apropriação (Vainer 2007; Zhouri 2011; Fuchs 2016) e nos impactos e formas de mitigação dos conflitos socioeconômicos (Castro et al. 2014; Fainguelernt 2016; Leturcq 2016; Fleury e Almeida 2013).

No entanto, há poucos estudos que analisem as medidas adotadas pelo Governo Federal para viabilizar a aceitabilidade social da obra, os quais requerem a investigação dos mecanismos de participação social fomentados no processo. No campo da avaliação de impacto ambiental, o Social License to Operate (SLO) tem sido o conceito mais utilizado, porém no caso de Belo Monte o processo de governança se estabeleceu em um contexto onde as responsabilidades entre os setores públicos e privados eram turvas, não transparentes e conflitantes, o qual colocou novos desafios para avaliar a pertinência da literatura referente aos mecanismos de participação social e de aceitabilidade social, particularmente, no que se refere às situações nas quais o papel do Estado se confunde com o papel de empreendedor privado, situação ainda pouco ilustrada na literatura (Fuchs, Leturcq e Grisotti 2016).

De acordo com Abers, Oliveira e Pereira (2017), sob o governo do PT, as agências que promoveram a participação social nos debates sobre grandes projetos de infraestrutura tiveram pouca influência sobre a tomada de decisão em comparação com os setores (públicos e privados) ligados, por exemplo, à construção civil. De acordo com as autoras, isso se deve às assimetrias de poder e relações desiguais existentes entre os grupos sociais, entre centroperiferia e, fundamentalmente, entre as agências estatais, limitando, com isso, a capacidade do estado (state capacity) em fomentar a participação social nesses processos.

Nesse artigo, analisamos o processo de aceitabilidade social da obra e das disputas em torno da responsabilização pelos impactos à saúde através da análise das memórias da Câmara Técnica de Saúde do Plano de Desenvolvimento Regional Sustentável do Xingu (PDRSX), que integra o Plano Amazônia Sustentável e a Política Nacional de Desenvolvimento Regional (PNDR), tendo como base para a análise o debate acadêmico sobre participação social. Para esse estudo analisamos os documentos institucionais do PDRSX: 33 memórias da Câmara Técnica de Saúde no periodo entre junho de 2013 a agosto de 2017; os registros das observações de algumas reuniões e das entrevistas com diferentes atores sociais, entre eles destacamos: membros do PDRSX (representantes de vários setores), funcionários das Secretarias Municipal e Estadual de Saúde, do Conselho Municipal de Saúde, do Ministério Público, da Defensoria Pública, das unidades de saúde e de vigilância epidemiológica, entre 2013 e 2018.

Apesar de aparentemente inovador, a execução desse Plano evidenciou as relações nebulosas, imprecisas e conflituosas entre os setores públicos e privados e como essas relações afetaram o processo de aceitabilidade social da obra e as dificuldades na identificação dos agentes responsáveis pela resolução dos problemas socioambientais ocasionados. 0 PDRSXé um exemplo de como o Governo Federal e os grupos pró-barragem tentaram viabilizar a aceitabilidade social da obra, pois como aponta Abers et al. (2017), pouco antes do início da licitação da usina, a coalização pró-barragem influenciou nesse processo e conseguiu em negociação com a Casa Civil um adendo no Termo de Referência da obra. Esse adendo obrigaria o consórcio responsável a investir 500 milhões de reais (através dos cofres públicos) no PDRSX, ao longo de vinte anos. Com base nesse fato e na propaganda governamental acerca da sustentabilidade do empreendimento, cabe a pergunta: o PDRSX deveria ser considerado um mecanismo para fomentar a sustentabilidade da região ou apenas uma barganha do Governo Federal em troca da aceitabilidade social da obra?

Além do reconhecimento das assimetrias de poder no interior do estado, proposta por 
Abers, Oliveira e Pereira (2017), é necessário compreender como as relações públicoprivadas se estabeleceram no processo de implantação de Belo Monte e de que forma essas relações geraram as indefinições nas atribuições de responsabilidades em relação aos impactos socioambientais; as fragilidades do Pacto Federativo brasileiro; a tendência para a sobreposição de esforços em participação social sem articulação com os mecanismos de participação e controle sociais já existentes enquanto políticas de estado, como os conselhos de saúde, meio ambiente e assistência social.

\section{Aceitabilidade social de projetos de desenvolvimento: o caso do PDRS do Xingu}

Através do Decreto Presidencial de 19 de novembro de 2009, o Grupo de Trabalho Intergovernamental do PDRSX foi instituído. De acordo com documentos oficiais esse grupo envolveu 19 órgãos e entidades federais, 27 órgãos do estado do Pará, governos municipais e sociedade civil. $^{2}$ Em 2010, o PDRSX foi institucionalizado oficialmente.

Em consonância com os propósitos da Política Nacional de Desenvolvimento Regional (PNDR) e do Plano Amazônia Sustentável, o PDRSX, buscava a atenuação e a mitigação dos efeitos socioambientais da construção da Usina Hidrelétrica de Belo Monte. É fundamental destacar que o PDRSX foi idealizado para servir como um modelo de projeto de sustentabilidade socioambiental para o país objetivando a redução dos impactos causados por grandes obras de infraestrutura através da aplicação de recursos financeiros em projetos propostos pela sociedade civil e governos (Federal, Estadual e Municipal).

Os principios norteadores que guiaram a elaboração do projeto do PDRSX basearam-se na premissa de que grandes obras de infraestrutura devem ampliar a participação do Estado em áreas onde, historicamente, sua presença foi marginal. O Plano visava a implementação de políticas públicas e o aumento da qualidade de vida dos aproximadamente 400 mil moradores das cidades que abarcam a área afetada por Belo Monte, a saber: Altamira, Anapu, Brasil Novo, Gurupá, Medicilândia, Pacajá, Placas, Porto Moz, Senador José Porfírio, Uruará e Vitória do Xingu.

A premissa defendida pelo Governo Federal era que a descentralização de políticas públicas para a região, através da parceria entre os três niveis de governo e a participação da sociedade civil no desenvolvimento do Plano garantiria a promoção do desenvolvimento social das localidades impactadas pela Usina Hidrelétrica (UHE) de Belo Monte.

No entanto, de que forma a participação social garantiria o desenvolvimento social da região se a construção da obra foi iniciada sem consultas prévias e sem o atendimento das condições previstas para a licença de instalação? Além disso, inúmeros ${ }^{3}$ estudos apontam que a sociedade civil têm historicamente poder de decisão mínimo em relação aos grandes projetos de infraestrutura no Brasil. Um exemplo disso, é a (in)capacidade dos atingidos terem suas demandas e preocupações ouvidas nas audiências públicas que decorrem nos processos de licenciamento ambiental de usinas hidrelétricas no País.

Durante o processo de licenciamento ambiental, os canais institucionais de participação destinados às populações atingidas por barragens são as audiências públicas, as reuniões do conselho de política ambiental (e, no caso de Belo Monte, as Câmaras Técnicas do PDRSX). Entretanto, Zhouri $(2011,15)$ avalia que as audiências públicas e as reuniões do Conselho inúmeras vezes

\footnotetext{
Brasil. 2010. Presidência da República. Casa Civil. Subchefia para Assuntos Jurídicos. Decreto n. ${ }^{\circ} 7340$ de 21 de outubro de 2010 . Institui o Plano de Desenvolvimento Regional Sustentável - PDRS do Xingu. Brasilia: Presidência da República. Casa Civil. Acessado em 22 de jul. 2019, http://www.planalto.gov.br/ccivil_03/ato2007-2010/2010/decreto/d7340.htm.

Brasil. 2010. Presidência da República. Casa Civil. Subchefia para Assuntos Jurídicos Plano de Desenvolvimento Regional Sustentável PDRS do Xingu. Brasília: Presidência da República/Casa Civil, 2010. Acessado em 22 jul. de 2019, http://www.casacivil.gov.br/.arquivos/ camaras-gts-e-comissoes/20110607_pdrsdoxingu.pdf.

3 A respeito ver Zhouri (2011), Vainer (2007), Fainguelernt (2016), Fuchs (2016), Ramos et al. (2018) e Comissão Mundial de Barragens (2005). Barragens e Desenvolvimento: um novo modelo para tomada de decisões. Em Tenotã-mõ: Alertas sobre as conseqüências dos projetos hidrelétricos no rio Xingu, Pará, Brasil, organizado por A. Oswaldo Sevá Filho, 301-316. São Paulo: International Rivers Network.
} 
atrapalham a "efetiva incorporação de propostas e demandas apresentadas pela população atingida, que acabam por recorrer frequentemente às esferas juridicas na tentativa de publicizar e tornar legítimos seus posicionamentos em relação aos empreendimentos". Neste contexto, Zhouri (2011) observa o aumento das intervenções do Ministério Público enquanto instância mediadora de conflitos que são ignorados e invisibilizados durante o licenciamento. No caso de Belo Monte, Vainer (2007) chama atenção ao fato do solicitante da licença-prévia ser um órgão do próprio Governo, o qual complexifica as atribuições de responsabilidades em relação às etapas de compensação socioambiental.

Belo Monte foi planejada e executada por meio de um protocolo que incentiva a relação entre o sistema público e o sistema privado (Castro et al. 2014). A transferência de responsabilidades do Governo Federal para a iniciativa privada através da figura da empresa Norte Energia S. A. (Nesa) ${ }^{4}$ e dos consórcios empresarias por ela contratados ${ }^{-5}$ abriu brechas para a sonegação de direitos e conflitos sobre as atribuições de responsabilidades entre Estado (Federal, Estadual e Municipal) e a iniciativa privada para com os atingidos, como será identificado adiante.

Devido à inexistência de uma figura jurídica oficial que representasse o PDRSX, os recursos financeiros da Norte Energia S.A. foram mantidos em conta bancária. Porém, juridicamente era o Comitê Gestor (CGDEX) do PDRSX que deliberava sobre o uso desses recursos. Inclusive, uma das pautas principais dentro do PDRSX referiase à possibilidade de se criar uma entidade independente para fazer a administração desses recursos e, ademais, trabalhar para captar outros tipos de financiamento, buscando alcançar a sustentabilidade financeira do Plano.

O PDRSX foi formado por oito Câmaras Técnicas (CT), ${ }^{6}$ um Comitê gestor (CGDEX), uma Coordenação Geral (CG) e uma Secretaria Executiva. As Câmaras Técnicas eram responsáveis por subsidiar as decisões do CGDEX no que diz respeito aos temas que fazem parte da sua pauta e, também, fornecer à Plenária do CGDEX a lista de projetos que deveriam ser apoiados pelo PDRSX. Sua composição era paritária entre representantes de governos e da sociedade civil.

O Comitê Gestor do PDRSX (CGDEX), composto de forma paritária por 15 membros representantes de órgãos governamentais e 15 membros representantes da sociedade civil, era a instância incumbida de monitorar a efetividade do PDRSX e validar as decisões tomadas nas CT. A coordenação-geral do CGDEX era composta por quatro membros, sendo um do Governo Federal, um do Governo do Estado do Pará, um prefeito da região (o presidente em exercício do Consórcio Belo Monte de Municípios) e um membro determinado pela sociedade civil. A execução das funções administrativas e operacionais do PDRSX ficava a cargo da Secretaria Executiva, exercida por empresas de consultoria socioambiental que eram contratadas diretamente pela Norte Energia S. A, com aprovação da Casa Civil da Presidência da República, do Comitê Gestor (CGDEX) e da Coordenação Geral do PDRSX.

Entre 2011 e 2018, 362 projetos foram aprovados nos 11 municípios contemplados no Plano? O valor total aprovado para investimento em projetos é de R\$ 277.386.149,55, valor que corresponde a 55\% do total de recursos disponibilizados pela Norte Energia S.A para o PDRSX. Verifica-se, assim, uma média anual de $\mathrm{R} \$$ 34.673.268,69 aprovados por ano e um valor

\footnotetext{
4 Empresa privada cuja composição acionária consiste em: Grupo Eletrobrás - Eletrobrás, Eletronorte e Chesf - (49,98\%); Entidades previdência complementar - Petros e Funcef - (20\%); Sociedade de propósito especifico - Belo Monte Participações S. A. (Neo Energia S A.) e Amazônia (Cemig e Light) - (19.77\%); Auto produtoras - Vale e Sinobrás - (10\%) e; Outras sociedades - J. Malucelli Energia - (0,25\%). Fonte: http://norteenergiasa.com.br.

5 Consórcio Construtor Belo Monte (CCBM) e Consórcio Montador Belo Monte (CMBM).

6 1: Ordenamento territorial, regularização fundiária e gestão ambiental; 2: Infraestrutura para o desenvolvimento; 3: Fomento às atividades produtivas sustentáveis; 3: Fomento às atividades produtivas sustentáveis, 4: Inclusão social e cidadania; 5: Monitoramento e acompanhamento da implementação das condicionantes previstas no Licenciamento Ambiental do empreendimento Belo Monte; 6 : Povos indigenas e comunidades tradicionais; 7: Saúde; 8: Educação

7 Cálculo não inclui os cinco projetos do CGDEX - sobre os quais não se tem informação online - e contabiliza os dois projetos do extinto Ministério da Pesca e Aquicultura, que foram cancelados.
} 
médio por projeto de R\$ 701.815.52 (Ramos 2018).

O poder público e as organizações da sociedade civil (cooperativas e ONGs) são as categorias que aprovaram maiores valores de projetos, $88 \%$ do total de recursos aprovados, sendo o poder público o maior beneficiado em comparação com os recursos financeiros destinados à sociedade civil.

Quando se especifica por setores, verifica-se que os governos municipais foram os que mais aprovaram recursos, $44 \%$ do total, seguidos das ONGs, $28 \%$ do total, e do Governo do Estado do Pará, 11\% do total de recursos. Esses três setores foram os responsáveis por mais de $80 \%$ do valor total aprovado.

Em agosto de 2018 constavam 67 projetos paralisados, $18 \%$ do total de projetos aprovados pelo PDRSX. Em entrevista, uma representante do Instituto de Avaliação (que substituiu a antiga gestão do PDRSX em 2016) relatou que, até essa data, os projetos eram aprovados pelos próprios membros das Câmaras Técnicas, os quais possuiam pouco conhecimento técnico e instrumentos válidos para realizar o controle e a avaliação dos projetos. Por essa razão, muitos projetos não apresentavam dados sobre sua execução, o que levou a uma série de auditorias que ainda estão em andamento.

Nesse contexto, cabe indagar: de que forma os objetivos do PDRSX foram atingidos? Dada a impossibilidade de investigar todas as CTs, nesse artigo, tentaremos responder à questão através da análise das memórias técnicas da Câmara Técnica da Saúde.

\section{Câmara Técnica da Saúde - CT7}

Durante uma reunião na CT-7, em novembro de 2014, na cidade de Altamira, ocorreu uma discussão entre o coordenador de Saúde da Norte Energia e o secretário de Saúde do município. 0 primeiro alegou que o aumento do número de casos de sífilis em gestantes ilustrava a falência das políticas públicas de Saúde (e Educação) na região, enquanto o segundo respondeu que esse aumento estava relacionado aos efeitos da obra na cidade, particularmente os 30.000 homens que vieram trabalhar na barragem, sem que as condições apropriadas e medidas de atenuação de impactos fossem realizadas anteriormente (Grisotti 2016). Esse caso é um exemplo das tensões entre as relações público-privadas e entre as políticas públicas (de Estado) e as condicionantes que deveriam ser executadas para a obtenção da licença de instalação da obra; tensões essas que ocasionaram a indefinição de responsabilidades para a mitigação de impactos, como veremos mais adiante.

A CT7 da Saúde aprovou 72 projetos no periodo de análise (2011 a 2018) sendo a CT com maior número de projetos aprovados. O valor total aprovado foi de R\$42.164.009,09. Os governos municipais aprovaram a maioria dos projetos e dos recursos, 64 projetos em um total de R\$ $37.124 .522,63$, o que equivale a $88 \%$ do valor total aprovado na CT. Em seguida, o Governo do Estado do Pará aprovou R\$ 2.675.986,46, seguido do Governo Federal, com R\$1.169.500,00 aprovados. Juntos, esses três setores aprovaram o equivalente a 97\% do total dos recursos da CT7. Em agosto de 2018 identificamos um número elevado daqueles "Em finalização", quarenta e seis. Muitos projetos dessa CT atrasaram a sua execução em relação ao cronograma original.

Em relação à diversidade de atores que acessaram os recursos, mapeou-se o total de 15 instituições que tiveram projetos aprovados, sendo que 11 desses proponentes são prefeituras dos municípios da área de abrangência do Plano. A prefeitura de Altamira foi a proponente que mais teve projetos aprovados, 13 , totalizando R\$ 10.971.343,47. Em seguida a prefeitura de Uruará teve nove projetos aprovados, totalizando R\$ 5.507.880,74. Em relação aos valores médios dos projetos por setor, os projetos do Governo do Estado do Pará possuem os maiores valores.

Com relação à composição dos membros presentes nas reuniões da CT-7, vimos que o Governo Federal teve como representantes mais assiduos funcionários ligados ao Ministério da Saúde. Os representantes do governo do estado do Pará foram, sobretudo, pessoas vinculadas à Secretaria de Saúde do Pará (Sespa) e da Secretaria Especial de Saúde Indigena (Sesai), 
que é vinculada ao Ministério da Saúde. No nivel municipal participaram os secretários de Saúde dos municípios da área de abrangência do PDRSX. Os participantes da sociedade civil foram, sobretudo, pessoas ligadas às ONGs da região, como por exemplo, o Movimento de Mulheres Trabalhadoras, Fundação Elza Marques e Fundação Viver, Produzir e Preservar.

Aanálise feita sobre a forma como transcorreram os debates das principais questões de saúde na CT-7, descritas nas Memórias, nos mostra que desde o início parece haver um "imbróglio" acerca da titularidade de responsabilização entre as esferas pública (composta pelas três esferas de governo e seus órgãos responsáveis) e o setor privado, caracterizado pelo consórcio Norte Energia, no que diz respeito às condicionantes socioambientais do empreendimento, às demandas trazidas pelos membros da CT-7 e aos projetos implementados. Esse "imbróglio" de responsabilidades já estava presente no âmago do licenciamento ambiental da obra, por meio da contraditória e confusa elaboração do Estudo de Impacto Ambiental de Belo Monte. O texto do Estudo de Impacto Ambiental (EIA) traz informações do Programa Saúde na Família e do Sistema de Vigilância Epidemiológica, como se esses programas fossem desenvolvidos pela Nesa, e menciona que os recursos públicos que financiam esses projetos são oriundos do empreendedor, em uma tentativa de confundir os programas do Ministério da Saúde como programas mitigatórios das novas demandas oriundas da barragem (Couto e Silva 2009). Essa questão fica ainda mais evidente pelo fato do EIA não trazer informações e dados para a identificação das possiveis medidas necessárias relacionadas aos serviços de saúde atreladas à construção da barragem. O documento parece sugerir, assim, que os efeitos negativos relativos à saúde humana na região recairiam sobre o poder público local e a sociedade civil (Couto et al. 2009). Apesar de previsto no EIA/Rima, as demandas de infraestrutura necessárias para absorver e mitigar o aumento populacional não foram executadas no tempo exigido tanto para a licença de instalação, quanto para a licença de operação. Vários documentos mostram a insuficiência dos estudos de impacto e o colapso do Sistema de Saúde durante o andamento das obras, entre eles, a análise do Painel de Especialistas (2009) e as Recomendações do Ministério Público Federal. ${ }^{8}$

O Plano de Atendimento à Emergência, o qual fazia parte da lista de condicionantes do empreendimento também foi terceirizado pela Nesa já no início do licenciamento ambiental (Couto et al. 2009), no que poderiamos chamar de terceirização da terceirização das responsabilidades dos impactos da obra.

A Nesa declara ter construido e entregue 30 unidades básicas de saúde e quatro hospitais dentro dos cinco municípios que compõe a Área de Influência Direta (AID) de Belo Monte, além de obras que visavam a melhoria da infraestrutura dos locais de atendimento de saúde. De acordo com a Prefeitura Municipal de Altamira, a Norte Energia finalizou e entregou o Hospital Geral de Altamira São Rafael (após o fim das obras da usina e do pico migratório); e somente 3 unidades básicas de saúde (UBS) foram entregues nos Reassentamentos Urbanos Coletivos (RUC).

Em várias Memórias apareceram discussões sobre de quem seria a responsabilidade pela manutenção e pelo custeio dos estabelecimentos de saúde após serem construidos e entregues ao município. A Norte Energia declarou, por exemplo, que não era sua responsabilidade a compra de equipamentos, que o PDRSX é um plano de desenvolvimento sustentável para a região, e seus recursos não vieram em substituição da responsabilidade de custeios relativos à área da saúde das três esferas do governo que envolve o Sistema Único de Saúde (SUS). Essa situação é exemplificada na discussão sobre o projeto que prevê a construção da casa de apoio às mulheres

\footnotetext{
8 Ministério Público Federal. 2016. Acessado em 15 fev. 2018, www.mpf.mp.br/pa/sala-de-imprensa/documentos/2016/recomendacao-do-mpf-para-abertura-do-hospital-do-mutirao-em-altamira-caso-belo-monte.
} 
gestantes no município de Brasil Novo:

(Prefeito Brasil Novo) A casa de gestantes não é mais responsabilidade do município e sim de uma instituição da sociedade civil.

(Representante da Sespa) A iniciativa do projeto foi da representante da sociedade civil e não houve comunicação sobre de quem seria a responsabilidade de manutenção da casa de apoio a gestante.

(Representante da soc. civil) a Nesa modificou o projeto sem comunicar a CT, bem como a obra foi mal executada, havendo várias irregularidades inviabilizando o uso da casa. (Memória CT-7 de 26 de março de 2015)

Desde as primeiras reuniões da CT-7, os membros advertiam para a falta de critérios para a construção dos projetos de infraestrutura, pois não estavam sendo desenvolvidos conforme o edital para a execução dos planos do PDRSX. Abaixo destacamos um trecho das Memórias onde essa situação é exemplificada com relação ao Projeto de Construção do Hospital de Porto de Moz:

(Representante do Ministério da Saúde) o projeto original sofreu alteração por parte do proponente e da empresa responsável pela construção do hospital. Empresa e prefeitura foram advertidas sobre a inviabilidade de alteração do projeto original da obra, e ainda assim a notificação foi desconsiderada.

(Representante da PM21) foram finalizadas as partes 1 e 2 da obra, porém, ainda há irregularidades, uma vez que o serviço que falta era uma contrapartida da prefeitura e não foi cumprida no prazo estipulado.

(Representante da Secretária Municipal de Saúde de Porto de Moz) o projeto não contempla as necessidades da obra e os serviços previstos que não foram fiscalizados ficarão sob responsabilidade da prefeitura e secretaria de saúde (Representante do Ministério da Saúde) o projeto de Brasil Novo não apresenta a escritura do terreno e nem os projetos arquitetônicos para a execução da obra. (Memória CT-7 de 26 de março de. 2015)

O monitoramento dos projetos aprovados no PDRSX, inicialmente, ficara a cargo da empresa PM21, contratada pela Nesa. A PM21 atuou no Plano até o ano de 2016, quando o Instituto Avaliação (IA) assumiu a função. Dentre as principais queixas registradas nas Memórias sobre a empresa PM21, estão: má execução e monitoramento dos projetos em andamento; denúncia dos representantes da sociedade civil da existência de acordos pessoais para o favorecimento de proponentes; questionamentos quanto à responsabilidade na execução dos projetos; existência de projetos sem comprovação financeira; e falta de entrega dos relatórios dos projetos em andamento.

Em 2016, quando o IA assumiu, a pedido do Governo Federal são elaborados novos principios fundamentais que deveriam constar nos futuros editais. Dessa maneira, o Instituto criou um compliance para o PDRSX, que se constitui como um conjunto de regras de compras e contratações, já utilizado pela Norte Energia, e que agora passa a integrar o PDRSX. De acordo com as falas dos responsáveis pelo Instituto Avaliação, o compliance seria uma ferramenta com principios minimos visando a estabelecer conformidade na adequação das esferas trabalhista, fiscal, financeira, ambiental, juridica e tributária. Essa mudança de princípios, segundo os representantes do IA, foi necessária pois na avaliação dos cinco anos do PDRSX se observou um número elevado de divergências e dúvidas se, de fato, os projetos e seus resultados estavam em consonância com os principios originais do desenvolvimento regional sustentável.

Apesar do montante de quase $\mathrm{R} \$ 40$ milhões de reais destinados à CT-7, a discussão sobre a insuficiência dos recursos do PDRSX para atender às demandas dessa $\mathrm{CT}$ foi consensual entre todos os seus membros. Dessa forma, muitos projetos que não tinham recursos suficientes para serem entregues foram custeados pelas prefeituras e, quando não houve essa possibilidade, relataram que muitas obras de infraestrutura e equipamentos comprados com recursos do PDRSX estavam sem uso, ou se deteriorando por falta de verbas. Além disso, os representantes municipais de saúde alertavam que existia uma grande porcentagem de impostos no valor total dos projetos que não era pago pelo PDRSX e que o custeio para manutenção dos hospitais e unidades de saúde, que deveriam ser pagos pelos governos, estavam 
sendo "empurrados" para o PDRSX. Neste sentido, os representantes do Ministério da Saúde e do BNDES (que contou com representantes em algumas ocasiões) defendiam que os recursos do PDRSX não deveriam servir para o pagamento desses custeios. Para elucidar essa problemática destacamos um trecho das Memórias.

(Representante da sociedade civil) preocupação com a situação dos recursos do PDRS Xingu: alguns projetos passados gastaram muito dinheiro com combustiveis, carros que foram destruidos logo na primeira semana de uso [...] O recurso do PDRS Xingu não tem o papel de manutenção e custeio de estabelecimento [...] (Representante da sociedade civil) não existe de onde retirar recursos para funcionar os estabelecimentos que não estão habilitados, o Hospital do mutirão ficou parado por um ano e estava deteriorado e que, por isso, os estabelecimentos não poderiam ficar parados e assim depreciados. (Memória CT-7 de 11 de agosto de 2016)

Sobre esse impasse dos custeios, Couto (2018) ressalta que resolver esse problema é o grande desafio das secretarias municipais de saúde da Área de Influência Direta de Belo Monte. De acordo com o estudo produzido pela Fundação Getúlio Vargas, ${ }^{9}$ as secretarias de saúde não possuíam recursos financeiros suficientes para a compra de equipamentos e de manutenção, e defenderam que o Ministério da Saúde fizesse a atualização do montante de repasse financeiro tendo em vista a nova realidade demográfica da região.

Com a mudança de governos municipais, entre os anos de 2015 e 2016, constatou-se que muitos projetos de compra de equipamentos foram superfaturados pelas antigas administrações, gerando uma indefinição por parte dos atuais gestores sobre como proceder, quem responsabilizar e a quem recorrer, como pode ser observado nos trechos extraidos das Memórias do CT-7 abaixo

(Novo prefeito de Uruará): seria inviável a transição amigável, pois a prefeitura de Uruará foi deixada em péssimo estado, inclusive com ausência de documentos, além de já saber que alguns veiculos oficiais foram dados como forma de pagamento do prefeito a um empresário local.

(Sec. Saúde de Uruará) pergunta se há possibilidade de firmar uma cláusula sobre o crime de responsabilidade, transferindo qualquer tipo de ação juridica ao representante da gestão passada. [...]

(Representante da sociedade civil) o comitê não é judicante e que não poderiam deliberar acima da lei, devendo-se recorrer ao Ministério Público. (Memória CT-7 de 8 de dezembro de 2016)

A maior parte dos debates registrados nas memórias do CT-7 refere-se à indefinição dos papeis e responsabilidades no que diz respeito às avaliações e execução dos projetos. Além disso, os representantes da empresa, em uma boa parte das reuniões, não estavam presentes, dificultando, assim, o encaminhamento e resolução das demandas. Existe uma série de críticas à atuação da Norte Energia contidas nas Memórias Técnicas, dentre as quais destacamos: falta de diálogo diretamente com a CT-7, somente com a Secretaria Executiva do Cgdex; falta de transparência em relação à compra de equipamentos; falta de resposta aos problemas apresentados nos projetos; "imbróglio" de responsabilidades com relação às demandas; demora na entrega do Hospital de Belo Monte (realizada posteriormente ao pico do contingente populacional que migrou para a região para trabalhar nas obras); denúncia de que os projetos não estavam sendo executados de acordo com o projeto original e o PBA (Plano Básico Ambiental) e sem aviso prévio à CT-7.

\section{Considerações finais}

Belo Monte é um caso singular para compreender as medidas adotadas pelo Governo Federal para viabilizar a aceitabilidade social de grandes obras de infraestrutura.

Além do reconhecimento das assimetrias de poder entre as agências estatais e do pouco poder de decisão daquelas que teriam capacidade de promover a participação social nos debates sobre o desenvolvimento econômico e social

\footnotetext{
9 Monzoni, Mario. 2015. Mapa dos caminhos. Saúde indígena. Uma análise do cumprimento de condicionantes da UHE Belo Monte relacionadas à saúde indigena e sua efetividade para o território. Fundação Getúlio Vargas (FGV). Acessado em 22 de jul. 2018, http:// indicadoresdebelomonte.eco.br.
} 
no Brasil, como apontado por Abers, Oliveira e Pereira (2017), identificamos, nesse estudo, que as indefinições e as disputas nas atribuições de responsabilidade pela mitigação dos impactos sociais e ambientais estão relacionadas: i) às formas como se viabilizaram as relações entre o estado e o consócio construtor privado. particularmente, no que se refere às situações nas quais o papel do Estado se confunde com o papel de empreendedor privado; ii) à forma como, na prática, está configurado o Pacto Federativo do Brasil, ou seja, como se sustentaram as relações entre os diferentes níveis de governo - Federal, Estadual e Municipal, incluindo também o nivel regional, já que a obra envolveu a criação de um consórcio de municípios em sua área de abrangência; e iii) às incompatibilidades entre as políticas de Estado e políticas de Governo, incluindo aqui a capacidade de governança intersetorial. Vimos na CT-7 a frequente confusão em torno das responsabilidades relativas ao gerenciamento do custeio de programas sociais, dos repasses de verbas e das tentativas de substituir os recursos governamentais destinados aos municipios pelos recursos do PDRSX.

O PDRSX foi proposto para fomentar o desenvolvimento da região e servir como um modelo de projeto de sustentabilidade, porém, através da análise das memórias da Câmara Técnica de Saúde constatamos que, ao invés de auxiliar na mitigação dos impactos socioambientais, os recursos do PDRSX foram utilizados como substitutos de algumas condicionantes que deveriam ter sido realizadas antes da obtenção das licenças prévia e de instalação da obra; ao mesmo tempo garantiu a aceitação social da obra, com o silenciamento de vários movimentos sociais contrários à instalação da barragem.

Criado como uma instância paralela e desarticulada de outros mecanismos institucionais de participação e controle social já existentes (como os conselhos de saúde, meio ambiente e assistência social), o PDRSX gerou uma justaposição de esforços em algumas áreas de um lado, e um possivel esvaziamento da participação social em outras. O resultado desse processo é visualizado no desperdício de recursos e na baixa eficácia dos projetos sociais executados.

Finalizado o Plano (ou os recursos) ficam as perguntas: qual a efetividade desse Plano para garantir a continuidade de projetos exitosos (se houver) e que tipo de avaliação oficial será realizada sobre o impacto deles na sustentabilidade regional do território afetado por Belo Monte?

\section{Referências}

Abers, Rebecca N., Marilia de Oliveira e Ana K. Pereira. 2017. Inclusive development and the asymmetric state: big projects and local communities in the Brazilian Amazon. The Journal of Development Studies 53 (6): 857872. https://doi.org/10.1080/00220388.2016.1208177.

Bermann, Célio. 2012. O projeto da usina Belo Monte: a autocracia energética como paradigma. Novos Cadernos NAEA 15 (1): 5-23. https://doi.org/10.5801/ ncn.v15i1.895.

Castro, Edna R. de. 2012. Amazônia: sociedade, fronteiras e políticas. Caderno CRH 25 (64): 9-16. http://dx.doi. org/10.1590/S0103-49792012000100001.

Castro, Edna R. de, Sara Alonso, Sabrina Nascimento, Larissa Carreira e Simy de A. Correa. 2014. Hidrelétricas na Amazônia e grandes dilemas postos à sociedade no século XXI. Papers do NAEA 418 (343): 26. Acessado em 30 de abr., 2019. http://Www.naea.ufpa.br/naea/ novosite/paper/418.

Cernea, Michael M. 1999. Why economic analysis is essential to resettlement. A sociologist's view. Economic and Political Weekly 34 (31): 2149-2158. Acessado em 11 jul., 2019. https://www.jstor.org/stable/4408255.

Couto, Rosa C. S. de. 2018. Hidrelétrica de Belo Monte: impactos na saúde. In Hidrelétrica Belo Monte: impactos na saúde, organizado por Rosa Carmina de S. Couto e Rosa A. Marin, 47-78. Belém: Editora Amazônica Bookshelf.

Couto, Rosa C. S. de e José M. Silva. 2009. As questões de saúde no estudo de impacto ambiental de Belo Monte. In Painel de especialistas: análise critica do estudo de impacto ambiental do aproveitamento hidrelétrico Belo Monte, organizado por Sonia Magalhães B. Santos e Francisco del Moral, 81-90. Acessado em 20 abr., 2019. http://www.internationalrivers.org.

Fainguelernt, Maíra. 2016. A trajetória histórica do processo de licenciamento ambiental da usina hidrelétrica de Belo Monte. Ambiente \& Sociedade 19 (2): 247-263. http:// dx.doi.org/10.1590/1809-4422ASOC0259R1V1922016.

Faoro, Raymundo. 2000. Os dons do Poder. São Paulo: Globo.

Fuchs, Vanessa Boanada. 2016. Blaming the weather, blaming the people: socio-environmental governance and a crisis attitude in the brazilian electricity sector. Ambiente \& Sociedade 19 (2): 221-246. http://dx.doi. org/10.1590/1809-4422ASOC026oR1V1922016. 
Fuchs, Vanessa B, Guillaume Leturcq e Márcia Grisotti. 2016. Acceptabilité sociale et place de la population lors de la construction du barrage de Belo Monte (Brésil). Éthique Publique. Revue Internationale d'éthique sociétale et gouvernementale 18 (1). http://doi : $10.4000 /$ ethiquepublique.2540.

Fearnside, Philip. M. 2017. Planned disinformation: the example of the Belo Monte dam as a source of greenhouse gases. In Brazil in the Anthropocene: conflicts between predatory development and enviromental policies, organized by Rejane Issberner and Philippe Lena, 1-20. Routledge, NewYork. Acessado em 10 ago., 2019. http:// philip.inpa.gov.br/publ_livres/Preprints/2017/Belo_Monte-emissions-Planned_disinformation-Preprint.pdf.

Fearnside, Philip M. 2001. Environmental impacts of Brazil's Tucurui dam: unlearned lessons for hydroelectric development in Amazonia. Environmental Management 27: 377-396. https://doi.org/10.1007/s002670010156.

Fleury, Lorena C. e Jalcione Almeida. 2013. A construção da usina hidrelétrica de Belo Monte: conflito ambiental e o dilema do desenvolvimento. Ambiente \& Sociedade 16: 141-156. https://doi.org/10.1590/S1414753X2013000400009.

Leturcq, Guillaume. 2016. Diferenças e similaridades de impactos das hidrelétricas entre o Sul e o Norte do Brasil. Ambiente \& Sociedade 19 (2): 267-290. http:// dx.doi.org/10.1590/180.9-4422ASOC0254R1V1922016.

Moran, Emilio F. 2016. Roads and dams: infrastructure-driven transformations in the Brazilian Amazon. Ambiente \& Sociedade 19 (2): 208-219. http://dx.doi. org/10.1590/1809-4422ASOC256V1922016.

Musacchio, Aldo e Sergio Lazzarini G. 2015. Reiventando o capitalismo de Estado. O Leviatã nos negócios: Brasil e outros paises. São Paulo: Portfolio-Penguin.

Ramos, André Marconato e Humberto Prates da Fonseca Alves. 2018. O conflito ambiental ao redor da usina hidrelétrica Belo Monte. Desenvolvimento e Meio Ambiente 46: 174-196. https://doi.org/10.5380/dma.v46io.50248.

Scudder, T. 1997. Social impacts of large dams. In Large dams: learning from the past, looking at the future. Workshop proceedings, organized by Tony Dorcey, Achim Steiner, Michael Acreman e Brett Orlando.

Vainer, Carlos B. 2007. Recursos hidráulicos: questões sociais e ambientais. Estudos Avançados 21 (59): 119-137. https://doi.org/10.1590/S0103-40142007000100010.

Zhouri, Andrea. 2011. As tensões do lugar: hidrelétricas, sujeitos e licenciamento ambiental. Belo Horizonte: Editora UFMG.

\section{Márcia Grisotti}

Doutora em Sociologia pela Universidade de São Paulo (USP), São Paulo, SP, Brasil, professora do Departamento de Sociologia e Ciência Política da Universidade Federal de Santa Catarina (Ufsc), Florianópolis, SC, Brasil.
Doutoranda do Programa de Pós-Graduação Interdisciplinar em Ciências Humanas da Universidade Federal de Santa Catarina (Ufsc), Florianópolis, SC, Brasil.

\section{André Marconato Ramos}

Doutorando do Núcleo de Estudos e Pesquisas Ambientais da Universidade Estadual de Campinas (Unicamp), Campinas, SP, Brasil. 